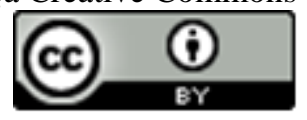

\title{
APRESENTAÇÃO DO DOSSÊ CIDADE, URBANIZAÇÃO E RELAÇÕES ÉTNICO RACIAIS NO BRASIL, ÁFRICA E DIÁSPORAS
}

\section{Reinaldo José de Oliveira ${ }^{1}$}

O Professor Doutor Andrelino Campos², geógrafo e intelectual negro, não está entre nós, ele foi ao encontro de seus ancestrais da diáspora africana, dos quilombos, guetos, periferias e favelas do Rio de Janeiro e do Brasil, ele nos deixou um legado para ser seguido, reflexões que são centrais para pensar o quadro dos movimentos sociais e as relações étnico raciais nos espaços da cidade e do urbano.

O dossiê Cidade, Urbanização e Relações Étnico Raciais no Brasil, África e Diáspora é dedicado ao Professor Andrelino Campos, pesquisador e docente que se dedicou às abordagens sobre a favela, o planejamento urbano, dos movimentos sociais negros e do "Direito à cidade". A Professora Cátia Antonia, docente do Centro de Formação de Professores da UERJ, Campus São Gonçalo, compartilhou importantes experiências em ensino, pesquisa e extensão com o Professor Andrelino Campos. A pesquisadora e amiga, fará as reflexões referente a produção do geógrafo e intelectual, deixando-nos, parcialmente, seu legado no presente dossiê.

Internamente, a ABPN, em sua história de aproximadamente vinte anos, tem as publicações “Questões Urbanas e Racismos” (2012), o Caderno Temático “Geografias Negras" (2020) e o presente dossiê "Cidade, Urbanização e Relações Étnico Raciais no Brasil, África e Diásporas". Considero a produção coletiva incipiente, em razão do histórico de mais de um século de segregação racial na sociedade brasileira.

\footnotetext{
1 Sociólogo, Doutor em Ciências Sociais PUC SP. E-mail: reinaldo.jose@uol.com.br; ORCID: https://orcid.org/0000-0003-3770-7862

${ }^{2}$ Falecido em 20 de maio de 2018.
} 
Frente ao quadro teórico metodológico sobre a cidade e as relações étnico raciais no Brasil, acredito que a ABPN, neste século XXI, precisará problematizar as reflexões e as lutas de Andrelino Campos, Milton Santos, Maria Carolina de Jesus, Abdias do Nascimento, Mariele Franco, Lélia Gonzales, dos movimentos sociais negros que atuam nos quadros das cidades, do urbano, saúde, dos direitos humanos para fins de transformar os lugares e territórios verdadeiramente democráticos e diversos.

Inicialmente, o primeiro texto do dossiê, tem como representação a homenagem ao Professor Doutor Andrelino Campos, de autoria da Professora Cátia Antonia. A autora, a partir da observação do percurso teórico metodológico e social do professor, analisa as trajetórias científicas sobre a espacialidade do negro na produção da segregação socioespacial em São Gonçalo e Rio de Janeiro. Na segunda seção, apresenta considerações reflexivas do autor sobre o movimento social negro, utilizando ferramentas filosóficas para a compreensão das formas de resistências em contextos urbanos e societários.

Posteriormente, do segundo ao sexto textos, estão classificados na primeira parte da organização: Conceitos Teóricos Metodológicos em Relações Étnico Raciais, Sociedade e Espaço Urbano.

A Professora Antonia dos Santos Garcia, apresenta o segundo texto, intitulado "Espaço, Gênero e Raça: Os Movimentos Sociais e os Desafios Contemporâneos" tema que considero central nesse século XXI. As reflexões da autora destacam as origens e histórias comuns da América Latina, Caribe e África, considerando que o sistema colonial escravista moldou nossas sociedades e cidades, e o Brasil nesse contexto. A construção eurocêntrica das sociedades e cidades no chamado Novo Mundo, tem seu tripé no colonialismo-escravismo, patriarcalismo-racismo e no mercantilismocapitalismo, que também produziu modelos explicativos que alimentam até hoje uma perversa engrenagem teórico-ideológica-política que favorece a reprodução de desigualdades e a perpetuação no poder dos grupos brancos hegemônicos.

Na sequência, o Professor João Vargas, pesquisador brasileiro radicado nos Estados Unidos, destaca em sua produção as ideias e conceitos sobre o quadro da antinegritude. Aqui, no texto intitulado "O cyborg e a escrava: geografias da morte e imaginação política na diáspora negra”, o autor mantém suas reflexões sobre a política antinegro. 
A partir de paradigmas de Vargas e Mbembe, Denílson Araújo de Oliveira, apresenta “A Questão Racial no Brasil: apontamentos teóricos para a compreensão do genocídio negro", tece importantes reflexões para compreender a relação entre racismo e necropolítica como dispositivos geradores do extermínio da população e da cultura negra no Brasil.

O quinto texto é de autoria do Professor Fábio Velame, "O Culto Egúngúm no Brasil - Diáspora, Ancestralidade e Resistência Negra nas Cidades Brasileiras", traz importantes contribuições sobre o urbano em articulação com o quadro social, histórico e cultural das religiões de matriz africana e afro-brasileira nas cidades do país.

O Professor Reinaldo José de Oliveira, apresenta o sexto texto "Segregação Racial e Desigualdades Urbanas nas Cidades Brasileiras: Elementos para uma Observação da Necropolítica”, fechando a primeira parte do dossiê.

As cinco produções refletem aspectos teóricos e metodológicos imprescindíveis no quadro das cidades, do urbano e das relações raciais, na perspectiva local, nacional, global e da diáspora.

A segunda parte Territórios e Territorialidades, Bairros e Cidades Negras no Brasil, contemplam cinco textos, que retratam as diferentes etapas, regiões e contextos dos espaços construídos pela população negra com o objetivo de se defender do racismo, para a produção das identidades e dos enfrentamentos diante das desigualdades, da segregação e da violência que atinge os corpos negros.

O sétimo texto é de autoria da pesquisadora e mestre Azânia Mahim Romão Nogueira, intitulado "A construção e apagamento de territórios negros". O texto aborda a territorialidade negra na ilha de Florianópolis, do passado e no presente momento, século XXI.

O oitavo texto, da mestra Daniele Vieira, apresenta o texto "Territórios Negros em Porto Alegre: Toponímia da emancipação negra no mapa de 1888".

Do sul para o sudeste, o Professor Henrique Cunha Junior e Professora Márcia Aparecida de Souza, retratam o nono texto do dossiê, intitulado "Bairros Negros de Natividade - Rio de Janeiro".

Henrique Cunha Júnior juntamente com Márcia Aparecida de Souza e os saberes e práticas de Luiza Maria de Souza, compõem o décimo texto, intitulado "Quintal de Dona Luiza Souza como parte da inserção da população negra na cidade". 
O Professor Sandro Correia, vai ao passado de sua infância para trazer as lembranças do território negro, o décimo primeiro texto "Curuzu, da Resistência a Requalificação Urbana, um Território Negro em Salvador - BA", trata das transformações socioeconômicas, políticas e culturais de um pedaço da cidade que reúne, parcialmente, as transformações urbanas de Salvador.

No décimo segundo texto, Reinaldo José de Oliveira, apresenta "Cidades Negras no Brasil: Territórios e Cidadania", problematiza as pequenas e médias cidades negras do país, em particular, na região que compreende o Recôncavo da Bahia, território que reúne as cidades com maior participação negra, conforme dados do IBGE (2010) e a literatura sobre relações étnico raciais e espaço (urbano e rural).

A terceira parte, Territórios, Quilombos e Educação, dois textos foram organizados para problematizar o momento histórico e atual. A Professora Rosy de Oliveira e a mestre Lilian Soares da Silva, apresentam o décimo terceiro texto "Território Quilombola de Cordoaria: exploração imobiliária e da resistência negra", localizado na cidade de Lauro de Freitas, vizinha a Salvador.

A Professora Lourdes Carril, no décimo quarto texto, intitulado "As noções de espaço e tempo a partir de uma cartografia quilombola", problematiza os saberes e práticas da educação escolar quilombola no processo de construção epistemológica da educação básica.

A quarta parte do dossiê, Segregação Racial, Espaço Urbano e Gênero, é a terceira área de investigação do dossiê que contempla seis textos, referente as urbes do Brasil e da Colômbia.

A mestre e pesquisadora colombiana, Lizete Sinisterra Ossa, no décimo quinto texto, intitulado "Espacio, Género y Raza: Estrategias Espaciales de Resistencia Afrofeminina em Colômbia", aborda a interseccionalidade de espaço urbano, classe social, gênero e raça para refletir a história e contemporaneidade de uma das principais urbes da sociedade colombiana.

Posteriormente, o décimo sexto texto é apresentado pelos professores Jaime Alves e Tathagatan Ravindran, intitulado "El capitalismo Racial, la zona de libre comercio de la Alianza del Pacífico y las Geografías Utópicas de la Antinegritud en Colombia". 
A Professora Josemeire Alves Pereira, apresenta o décimo sétimo trabalho, intitulado "A Eloquência do Silêncio: Racismo e Produção de Esquecimento sobre a População Negra em Narrativas na memória das Cidades".

No décimo oitavo texto, a arquiteta e mestre Lisandra Mara, em trabalho intitulado "Lei e Discriminação na Produção da Cidade Segregada", também observa a urbe de Belo Horizonte. Lisandra, por intermédio da arquitetura e urbanismo e Josemeire, pelas narrativas da história, observam e tecem reflexões sobre a cidade negra, Belo Horizonte.

As Professoras Maria Nilza, da Silva e Mariana Panta, no décimo nono texto, intitulado "Segregação Urbana e Racial na Cidade: O "Lugar" da População Negra em Londrina", analisam os elementos sociais que caracterizam a segregação da população negra em uma das principais urbes do estado do Paraná.

O Professor Reinaldo José de Oliveira, no vigésimo texto, intitulado "São Paulo cidade negra no século XXI”, apresenta a relação entre territórios e territorialidades negras e a segregação racial para melhor delinear as transformações da hierarquia socioeconômica, política e cultural de negros e brancos na principal urbe do capitalismo nacional em solo paulistano. Parte do cenário do racismo e das desigualdades, são elementos que caracterizam a necropolítica na cidade de São Paulo.

Na cidade negra de Salvador, o Professor Edson Dias Ferreira, apresenta o vigésimo primeiro texto, "O Sentido da Festa: Olhar Retrospectivo sobre o Ciclo do Verão Baiano Vinte anos depois". No referido texto, o autor analisa o processo histórico das grandes transformações festivas e urbanísticas da terceira maior cidade do Brasil, sobrerepresentada por homens e mulheres negras na geografia social.

No presente dossiê, as urbes de Salvador, Rio de Janeiro, São Paulo, Belo Horizonte, Londrina, as cidades brasileiras e colombianas, são cenários da segregação étnico racial, da colonização ibero americana, do escravismo e do momento atual, sobretudo da estrutura que caracteriza a política antinegro e da necropolítica.

Acredito que a referida produção poderá proporcionar avanços na produção de conhecimento científico de combate ao racismo e às desigualdades nas urbes do país. Considero a promoção de políticas públicas no âmbito das cidades, do urbano e do rural, centrais para as grandes transformações do século XXI. 
A quinta parte do dossiê, Movimentos Sociais, Saúde e Cidades, reúne quatro textos que retratam o protagonismo das gerações do século XX e do momento atual.

No vigésimo segundo texto, "Mulheres Negras e formulação de Políticas Públicas: Triagem Neonatal para Anemia Neonatal", as Professoras Berenice Kikuchi, Maria Lúcia Ivo e Ana Rita Barbieri, analisam o protagonismo de mulheres negras na periferia da zona leste de São Paulo, frente ao cenário de construção de políticas públicas de cuidados e atenção básica da anemia falciforme.

Os docentes Regina Marques de Souza Oliveira, Núbia Reis Pinto e Reinaldo José de Oliveira e os pesquisadores Railton da Conceição Santos e Jaqueline Alves Fonseca, apresentam o vigésimo terceiro texto "Saúde Mental em Territórios Segregados: Clínica da Violência Racista-sexista e Formação em Psicologia”. O texto em questão irá observar a saúde mental da população negra na cidade, com destaque nas escutas dos pesquisadores para melhor delinear o cuidado dos corpos negros diante do sofrimento do racismo e da violência.

A escrita do vigésimo quarto texto é de Regina Marques de Souza Oliveira, "Indígenas e Negros nas Cidades: Escuta Clínica para a Saúde Mental e Ciência Psicológica”. Assim como o texto anterior, nessa reflexão a autora tece importantes considerações sobre o quadro psíquico, mental e subjetivo das matrizes indígenas, africana e afro-brasileira. Na perspectiva histórica e contemporânea da violência e da necropolítica dos corpos negros e indígenas, é urgente para os estudos do presente dossiê abordar a saúde mental nas cidades, do âmbito local e global.

A pesquisadora Jaqueline Souza, e os docentes Regina Marques de Souza Oliveira e Reinaldo José de Oliveira, fecham o dossiê com o vigésimo quinto texto "Migrações, Colonialismo e Efeitos Psicossociais em Territórios Litorâneos NegroIndígenas da Bahia". O texto trata da imigração estrangeira de europeus e norteamericanos no Sul da Bahia, em cidades negras que vivem a exploração do capitalismo global e local no espaço urbano, social e turístico.

O dossiê CIDADE, URBANIZAÇÃO E RELAÇÕES ÉTNICO RACIAIS NO BRASIL, ÁFRICA E DIÁSPORAS é dedicado ao Professor Andrelino Campos, que protagonizou a práxis e a retórica da luta incessante do "Direito à Cidade", em especial, dos insubordinados dos morros, favelas, periferias, guetos, segregados, aos homens e mulheres negras que edificaram as urbes do Rio de Janeiro, São Gonçalo, Niterói, São 
Paulo, Salvador, Belo Horizonte, Porto Alegre, Florianópolis, Londrina e as pequenas, médias e grandes cidades do Brasil e do mundo.

Compreender a formação do sujeito não é uma das tarefas fáceis na história socioespacial brasileira. As políticas de desqualificação dos movimentos populares, sobretudo de negros e negras, de luta pela terra e contra a propriedade de grandes latifúndios, sempre foram práticas combatidas pelos grupos hegemônicos, onde estes personagens aparecem quase sempre como coadjuvantes. Os espaços de resistência constituídos por negros(as) e pardos no urbano ou no campo, por meio do campesinato, foram alvo de ataques sistemáticos ao longo dos últimos séculos, como, por exemplo, a transmutação de quilombos em favela, que não fez reduzir os estigmas que pairam sobre os negros e negras no Brasil. $\mathrm{O}$ acesso desigual ao mundo do trabalho, à propriedade da terra, à educação e à saúde, além de muita dificuldade de se localizar nas cidades e/ou no campo (...) (CAMPOS, 2013, 227).

As reflexões acima de Andrelino Campos, representam parte da produção do presente dossiê. Nesse século XXI, dentre as hipóteses teórica e prática, provavelmente, a luta se inscreverá em duas frentes: de um lado, o enfrentamento da necropolítica e da política antinegro e, de outro lado, a construção de cidades e sociedades baseadas em direitos à igualdade e às diferenças sem as históricas opressões de classe social, gênero e etnia raça (VARGAS, 2016; OLIVEIRA, 2018).

\section{REFERÊNCIAS BIBLIOGRÁFICAS}

CAMPOS, Andrelino. Do Quilombo à favela: a produção do espaço criminalizado no Rio de Janeiro. Rio de Janeiro, Bertrand Brasil, 2007.

.Entre a pessoa e o sujeito do conhecimento: algumas considerações sobre o movimento negro no contexto socioespacial. In: A Cidade e o Negro no Brasil: Cidadania e Território. São Paulo, Editora Alameda, 2013.

MBEMBE, Achille. Necropolítica, Rio de Janeiro, 2016.

OLIVEIRA, Reinaldo José de. Novos e Antigos Cenários da Segregação e das Desigualdades da População Negra em São Paulo. In: Maura Pardinini Bicudo Véras (organizadora), Desigualdades Urbanas, Segregação, Alteridade e Tensões em Cidades Brasileiras. Jundiaí, SP, Paco Editorial, 2018.

SANTOS, Renato Emerson dos (Org.). Diversidade, espaço e relações étnico-raciais - O negro na Geografia do Brasil, Belo Horizonte, Editora Autêntica, w007. 
VARGAS, João da Costa. Antinegritude. Belo Horizonte e Cruz das Almas, Editora Fino Trato e EDUFRB, 2016.

Recebido em: 22/09/2020

Aceito em: 30/10/2020 